\title{
Teachers' Competencies in the Design and Delivery of Chemistry Practical Work
}

\author{
Chama Sarah ${ }^{1} \quad$ Nachiyunde Kabunga ${ }^{2}$ \\ 1. Mukuba University, School of Natural Sciences, P.O.Box 20382, Kitwe, Zambia \\ 2. The University of Zambia, School of Education, P.O. Box 32379, Lusaka, Zambia
}

\begin{abstract}
The aim of the study was to investigate chemistry teacher's competencies in the design and delivery of chemistry practical work in selected schools of Kitwe District. The objectives of the study were to: determine the nature of chemistry practical activities designed and delivered by teachers, establish the range of science process skills developed through chemistry teacher designed practical activities. The study was qualitative and a case study design was used. The target population was chemistry teachers teaching the two chemistry syllabi; pure Chemistry (5070) and Science (5124) a combination of Chemistry and Physics in selected secondary schools of Kitwe district. The sample comprised six chemistry teachers and 24 pupils drawn from three secondary schools. The study involved the use of: observation schedule, semi-structured interview schedule, focus group discussion guide and document analysis schedule to collect data. The findings showed that most of the practical activities designed by teachers were procedural in nature hence they were characterised by learners following laid down procedures. It was also noted that the focus of most of these practical activities was to expose learners to pieces of apparatus, verify and confirm what was discussed during theory lessons. The types of science process skills and how they were developed was linked to the nature of the observed practical activities. For this reason, these science process skills were not effectively developed to the extent that could lead learners to construct their own understanding of concepts. The findings of this study are likely to be informative to chemistry teachers, secondary school heads of science department and science teacher educators.
\end{abstract}

Keywords: Teacher's competency, Science Process Skills, Practical work, Designing

DOI: $10.7176 / \mathrm{JEP} / 10-23-03$

Publication date: August $31^{\text {st }} 2019$

\section{Introduction}

Chemistry is a science that describes matter, its properties, the changes it undergoes and the energy changes that accompany those processes. Jimmi (2014:313) describes teachers' competency as a "set of knowledge, skills and proficiency in creating meaningful experiences when organising an activity". This suggests that teachers' ability to design and deliver practical work is key in enhancing learner's conceptual understanding and acquisition of science process skills. On the other hand skills and competency of teachers in handling the instructional process with the help of pedagogy, teaching and learning aids is of great importance in the learning process (Katane and selvi, 2006).

\subsection{Background of the study}

The teaching of Chemistry in secondary schools is guided by two syllabi; 5070 and 5124 . The main difference in these two syllabi is that 5070 is only composed of Chemistry, while 5124 has Chemistry and Physics components (CDC, 2013). Statistics from the Examination Council of Zambia (ECZ) covering the years 2006 to 2010 and 2013 to 2016 show that learner's performance in 5070 and 5124 has been consistently poor. The 2014 examination performance report also reveals that learners' have continued to perform poorly in science country wide. The report further points out that the average performance fell below the pass mark of $40 \%(\mathrm{ECZ}, 2014)$. The chief examiners reports for 2015 and 2016 specifically indicate that the general performance in practical work was poor. The reports highlight that learners had challenges: making observations and undertaking a critical analysis of their observations, drawing conclusions from their observations and applying their theoretical knowledge to explain observations and results from experiments.

\subsection{Statement of the Problem}

A number of studies have been done that highlight class size, inadequate teaching and learning materials, lack of conventional laboratories and lack of support for teachers as among other factors contributing to learners' low performance in science (Nkoya, 2008; Chocha et al, 2014). Conceptual understanding of chemistry is influenced by the opportunities given to learners to experience scientific phenomena through hands-on activities. However, learners' poor performance in practical work may be attributed to the skill and tact of Chemistry teachers in creating and implementing meaningful practical activities (Katane and Selvi, 2006). It is against this background that the study was done in order to investigate Chemistry teachers' competencies in the design and delivery of practical work. 


\subsection{Purpose of the Study}

The purpose of the study was to investigate chemistry teacher's competencies in the design and delivery of practical work in selected secondary schools of Kitwe district of Copperbelt province of Zambia.

\subsection{Objectives}

i. To determine the nature of Chemistry Practical Activities designed and delivered by Chemistry teachers.

ii. To establish the range of Science Process Skills developed through chemistry teacher designed practical activities.

\section{Literature review}

Olufsen et al (2015:87) defines practical work as "any type of science teaching and learning activity in which students, working either individually or in small groups are involved in manipulating and/ or observing real objects and materials". Practical work has a key role in chemistry education from a lower level through to university. One of the features of chemistry as a science is the aspect of doing practical work. This is the case because the aim of chemistry is to increase our understanding of the composition, properties and changes of matter. Therefore, claims and explanations in chemistry should be substantiated by observations and interaction with materials. On the other hand Millar (2004) says that there are many benefits in engaging students in laboratory and other practical work. Among the many benefits in chemistry, practical work engages all the five sense of the learners.

Other scholars (Hodson, 1991; Osborne, 1993; Millar; 2010; Mwangi; 2016) have indicated that the way practical work is currently used in the teaching and learning of science is ineffective and it does not contribute very much to learners' conceptual understanding. Hodson (1991:176) states that "as practised in many schools, it [practical work] is ill-conceived, confused and unproductive. For many children, what goes on in the laboratory contributes little to their learning of science ..." This calls for the teacher to be skilful in designing practical activities that are meaningful for the learners.

Millar (2004) gives an outline of the characteristics of an ideal design of practical activities. A practical activity should have clear learning objectives. The other aspect is that it should have a limited number of intended learning outcomes. This is important in keeping the learners focused on the skills and knowledge that the task designer wants them to acquire. If learners need a specific skill for the task then they should be exposed to opportunities to learn it before the practical activity so that it does not get in the way of the intended learning (Abrahams and Millar, 2009). An effective practical activity encourages the use of affordable and available equipment.

There are various categorisation of practical work used in secondary schools and these may include; teacher demonstrations, class practicals and learners working on similar tasks individually or in small groups (Wellington, 2002). On the other hand Olufsen et al (2015) contends that practical work can be classified as; teacher demonstrations, cook book/recipe style experiments and open ended/inquiry experiments. But what is frequently used in secondary schools is the recipe style. Though popular, this way of conducting practical work has been criticised for not giving learners an opportunity to construct their own knowledge and understanding of the chemistry concepts (Laughran and Gunstone, 2000; Millar, 2004).

One of the goals of doing practical work is to help students develop and acquire science process skills. These skills enable students to collect data, engage in different scientific investigations and come up with evidence to help answer scientific questions (Machina, 2012). Most of the studies reviewed have acknowledged the importance of practical work in the teaching and learning of chemistry and science in general. But have not conclusively provided answers to questions relating to the nature of practical work designed by teachers. Additionally, methodologies used have focused so much on self-reports through the use of questionnaires, Thus, the current study employed methods that focused more on understanding teachers' competence in the design and delivery of chemistry practical work by visiting and observing practical lessons in their natural setting so as to contribute to the body of knowledge.

\section{Theoretical framework}

The study was informed by the core constructs of science as inquiry and the constructivism theory. Scientific inquiry refers to methods and activities that lead to the development of scientific knowledge (Schwartz, Lederman and Crawford, 2004). National Research Council (2000) describes scientific inquiry from the classroom context as a set of abilities and understandings that include asking scientifically oriented questions, giving priorities to evidence in responding to questions, formulating explanations and connecting to scientific knowledge and justifying explanations

The constructivism theory of learning stipulates that learners are active in the construction of their knowledge. Vygotsky (1978) amplifies this point when he states that social interactions are important in the construction of this knowledge. The theory focuses on a number of teaching/learning methods such as inquiry, problem solving, discovery and project work (Schunk, 2012). All these methods place emphasis on the active participation of the 
learner. This theory underpins the use of hands-on activities such as practical work in the teaching and learning process of science. Practical work involves learners to work either individually or in small groups in manipulating and/or observing real objects and materials (Abrahams and Reiss, 2012). Teacher's competencies in the design and delivery of Chemistry Practical work is informed by science as inquiry and constructivism through:

- Properly planned and properly executed Chemistry practical activities. This helps learners to construct their own knowledge through hands-on activities.

- Giving priority to generation of evidence for scientifically oriented questions.

- Developing ability of learners to formulate scientifically sound explanations of their observations.

\section{Methodology}

\subsection{Research Design}

A case study design was employed in conducting this study. A case study focuses on a single unit to produce an in-depth description that is rich and holistic. A unit can be an individual, a group, a site, a class, a policy, a process, an institution, a community or town (Merriam, 1998). The design enhances an in-depth exploration of a bounded system. This study used geographical parameters as definition for a bounded system (Cohen, Manion and Morrison, 2007). The design also allowed the researcher to collect detailed data using a variety of data collection instruments and procedures (Yin, 2012). This provided an opportunity to warrant trustworthiness and credibility of data through triangulation.

\subsection{Population and Sample of the Study}

This study targeted Chemistry Teachers teaching using 5070 and 5124 syllabi in selected secondary schools in Kitwe district of the Copperbelt Province of Zambia. The chemistry teachers in these schools were chosen because the schools had operational science laboratories and they were ready to be observed during their Chemistry practical activity lessons. In order to get more comprehensive data, the study included pupils from the respective classes were lesson observations were done.

The sample comprised 6 chemistry teachers and 24 pupils drawn from three secondary schools that offer 5070 and 5124 syllabi. The sample was representative enough considering the nature, purpose and data collection methods such as observations that require a lot of time (Ary, Jacobs and Sorensen, 2010). The sample was large enough for a case study.

\subsection{Sampling Techniques}

In this study purposive sampling was used to select the 6 Chemistry teachers. The researcher was satisfied that this technique provided a sample of participants that were teaching 5070 and 5124 hence they were considered information rich in relation to the topic under study. The 24 pupils were selected from the classes where lesson observations were done based on their participation during the practical activity lesson. Grade 11 pupils were preferred in this study because at this level they have had acquired the skills in the handling of apparatus and chemicals involved in Chemistry practical activities.

\subsection{Research Instruments}

The study employed four instruments and these are observation schedule, document analysis, semi-structured interview schedule and focus group discussion. Observation schedule was used because it gave the researcher an opportunity to have a complete description of behaviour in a specific and natural setting (Ary, Jacobs and Sorensen, 2010). Document analysis was used to gain information about certain aspects that could not be observed, documents such as chemistry syllabi, chemistry schemes of work, lesson plans and practical activity worksheets. Semi-structured interview schedule composed of open ended questions and its focus was to follow up on the objectives of the practical activities and how science process skills development was enhanced. Lastly, focus group discussion guide was used to clarify specific matters that arose from observations and document analysis.

\subsection{Data Collection}

The study mainly used lesson observation to establish the types of practical activities designed and delivered by the chemistry teachers. The lesson observations were complimented by focus group discussions, interviews and document analysis so as to get insights of teachers as well as pupils and their focus as they conducted the handson activities.

\subsection{Data Analysis}

The data collected from observations, interviews, document analysis and focus group discussions was categorised and analysed. Firstly, the data was sorted and arranged into different categories from various instruments. Secondly all the data was read in order to get a general sense and accord the researcher an opportunity to reflect on its overall meaning thereafter themes were generated (Merriam, 1998). 


\section{Results of the Study}

The study results are presented in line with the objectives: (a) the nature of chemistry practical activities designed and delivered by chemistry teachers, (b) the range of science process skills developed through practical activities designed and delivered by chemistry teachers

5.1 Nature of chemistry practical activities designed and delivered by chemistry teachers

Table 1: Types of practical activities designed by chemistry teachers

\begin{tabular}{|c|c|c|}
\hline Characteristics of practical activity & $\begin{array}{l}\text { Type of practical } \\
\text { Activity }\end{array}$ & Frequency \\
\hline $\begin{array}{l}\text { - Learners following a list of steps provided by teachers } \\
\text { - } \quad \text { Learners not allowed to come up with an alternative method } \\
\text { - The required reasonable amount of time given to learners to do } \\
\text { the activity }\end{array}$ & Procedural & 11 \\
\hline $\begin{array}{l}\text { - Learners do a specific task that is easily organised by the } \\
\text { teacher } \\
\text { - } \quad \text { Learners manipulate limited materials and apparatus } \\
\text { - Teacher may do the activity alone as a demonstration or choose } \\
\text { - } \quad \text { Leme pupils do so } \\
\text { Learners working towards confirming an idea }\end{array}$ & Illustrative & 0 \\
\hline $\begin{array}{l}\text { - Teacher presents a scientific problem to learners } \\
\text { - } \\
\text { Teacher providing various materials and apparatus for pupils to } \\
\text { use } \\
\text { - Learners openly using various procedures to conduct the activity } \\
\text { Learners working towards solving a problem with less guidance } \\
\text { from the teacher. }\end{array}$ & Investigative & 1 \\
\hline
\end{tabular}

Out of the 12 practical lessons observed and worksheets analysed 11 were procedural and only one was investigative. Pupils were guided by an outlined number of steps to follow when conducting practical activities. It was also observed that learners were working in small groups. When asked during the focus group discussion which is better, working in groups or individually, majority of the learners responded that working in small groups was better compared to working individually because they were able to share ideas and it also helped them to finish the task on time.

During a focus group discussion with the teachers to discuss matters that arose during the observations, teachers were asked to indicate what they thought as the best way of presenting practical activities. The common response was that learners should do the practical activity by following guiding steps. For example Teacher D (TD) stated that:

"The best way of delivering practical activity is to allow pupils to carry out the experiment themselves and a worksheet is necessary because they have to follow instructions..."

It was observed that the purpose of the practical activities designed by the chemistry teachers was either to expose the learners to pieces of apparatus and their use so that learners will be able to manipulate them later and to confirm what was discussed in the theoretical lessons to actually what happened during the practical activities. Thus, these practical activities did not focus on helping learners to understand the chemistry concepts. Interviews were used to follow up these observations. The participants were asked what the purpose of their activities was and the following response stood out;

"Learners learnt how handle the apparatus, some of them did not even know the parts of the apparatus that they were using".

\subsection{Range of science process skills developed through teacher designed practical activities}

The finding suggests that the practical activities designed by chemistry teachers focused on the development of basic science process skills rather than an integration of both basic and integrated science process skills. This was the case due to the nature and purpose of these practical activities.

Tables 1, 2 and 3 show the range of science process skills developed $(\checkmark)$ through practical activities designed by chemistry teachers on specific topics that were observed. 
Table 2: Range of science process skills developed through qualitative analysis practical activity

\begin{tabular}{|l|l|c|}
\hline \multicolumn{1}{|c|}{ Practical activity } & \multicolumn{1}{|c|}{ Science process skills } & Observed \\
\hline \multirow{4}{*}{$\begin{array}{c}\text { Qualitative } \\
\text { Analysis }\end{array}$} & Observation & $\checkmark$ \\
\cline { 2 - 3 } (Identification & Classification & $\checkmark$ \\
\cline { 2 - 3 } of cations \& anions $)$ & Communication & $\mathbf{x}$ \\
\cline { 2 - 3 } & Measuring & $\mathbf{x}$ \\
\cline { 2 - 3 } & Predicting & $\mathbf{x}$ \\
\cline { 2 - 3 } & Inferring & $\mathbf{x}$ \\
\cline { 2 - 3 } & Using numbers & $\mathbf{x}$ \\
\cline { 2 - 3 } & Identifying and controlling variables & $\mathbf{x}$ \\
\cline { 2 - 3 } & Interpreting data & $\mathbf{x}$ \\
\cline { 2 - 3 } & Formulating hypothesis & $\mathbf{x}$ \\
\cline { 2 - 3 } & Defining operationally & $\checkmark$ \\
\cline { 2 - 3 } & Experimenting & $\checkmark$ \\
\hline
\end{tabular}

Table 3: Range of science process skills developed through volumetric analysis practical activity

\begin{tabular}{|c|l|c|}
\hline Practical activity & \multicolumn{1}{|c|}{ Science process skills } & Observed \\
\hline \multirow{4}{*}{$\begin{array}{l}\text { Volumetric } \\
\text { Analysis }\end{array}$} & Observation & $\checkmark$ \\
\cline { 2 - 3 } (Titration) & Classification & $\mathbf{x}$ \\
\cline { 2 - 3 } & Communication & $\checkmark$ \\
\cline { 2 - 3 } & Measuring & $\checkmark$ \\
\cline { 2 - 3 } & Predicting & $\mathbf{x}$ \\
\cline { 2 - 3 } & Inferring & $\mathbf{x}$ \\
\cline { 2 - 3 } & Using numbers & $\mathbf{x}$ \\
\cline { 2 - 3 } & Identifying and & $\checkmark$ \\
\cline { 2 - 3 } & controlling variables & $\checkmark$ \\
\cline { 2 - 3 } & Interpreting data & $\mathbf{x}$ \\
\cline { 2 - 3 } & Formulating hypothesis & $\mathbf{x}$ \\
\cline { 2 - 3 } & Defining operationally & $\checkmark$ \\
\cline { 2 - 3 } & Experimenting & $\checkmark$ \\
\end{tabular}

Table 4: Range of science process skills developed through preparation of soluble salts practical activity

\begin{tabular}{|c|l|c|}
\hline \multicolumn{1}{|c|}{ Science process skills } & Observed \\
\hline \multirow{4}{*}{ Practical activity } & \multicolumn{1}{|c|}{$\checkmark$} \\
\cline { 2 - 3 } & Observation & $\checkmark$ \\
\cline { 2 - 3 } & Classification & $\checkmark$ \\
\cline { 2 - 3 } & Communication & $\mathbf{x}$ \\
\cline { 2 - 3 } & Measuring & $\mathbf{x}$ \\
\cline { 2 - 3 } & Predicting & $\mathbf{x}$ \\
\cline { 2 - 3 } & Inferring & $\mathbf{x}$ \\
\cline { 2 - 3 } & Using numbers & $\mathbf{x}$ \\
\cline { 2 - 3 } & Identifying and controlling variables & $\checkmark$ \\
\cline { 2 - 3 } & Interpreting data & $\mathbf{x}$ \\
\cline { 2 - 3 } & Formulating hypothesis & $\mathbf{x}$ \\
\cline { 2 - 3 } & Defining operationally & $\checkmark$ \\
\cline { 2 - 3 } & Experimenting & $\mathbf{2}$ \\
\hline
\end{tabular}

\section{Discussion}

The study revealed that most of the practical activities observed were procedural in nature. In most cases the role of these activities was to develop manipulative skills of how to use the pieces of apparatus. Abraham and Millar (2009) emphasises the need for teachers to have a clear understanding of the reasons for doing practical work. This is due to the fact this type of practical work does not challenge learners to think about the purpose of the experiment or the sequence of the steps involved (Chiapetta and Koballa, 2010). This finding resonates with what Olufsen et al (2015) stated that what is frequently used in secondary schools is the recipe style of practical work. Further procedural type of practical activities are said to be an ineffective way of learning science concepts because they do not provide sufficient opportunities for learners to be actively involved in knowledge construction and understanding ( Millar, 2004).

It is clear from the study that the practical activities observed mostly developed basic science process skills 
in one way or the other. Though basic science process skills are core to the process of science, integrated science process skills such as predicting, inferring, formulating hypothesis, controlling and manipulating variables and defining operationally are also crucial to the learning of chemistry as a science because they enable learners to think scientifically and critically by resolving their cognitive conflicts as they make predictions and state their inferences about the practical activities being conducted (Mwangi,2016). When teachers were asked how they enhanced the development of science process skills, the common response was by doing hands-on activities, learners will learn the skill of how to handle the apparatus and make observations. This may imply that teachers did not fully understand the role of practical activities in the development of science process skills and its use in the creation of knowledge through investigation consequently the role of practical work in effective teaching and learning of chemistry (Emereole, 2009; Mbewe, Mumba and Chabalengula, 2010).

Practical activities conducted were only; volumetric analysis, qualitative analysis and preparation of salts. In the actual sense the syllabi and schemes of work showed that there were more than 10 areas where practical activities would have been drawn from. Owing to the fact that most of the practical activities were procedural, coupled with lack of variety only a few mostly basic science process skills were developed or rather used by the learners as they engaged in the practical activities. It also suffices to mention that the questions asked did not encourage learners to think critically, create a link between observations made and data collected in order to fully understand the chemistry concepts (Ituma, Twoli and Khatete, 2015). Hodson (1991) notes that the way practical work is conducted in secondary schools does not productively help learners to learn and understand science concepts. However, if comprehensively designed practical activities might be an effective way of teaching chemistry topics, consequently leading to improved performance in 5070 and 5124.

\section{Conclusion}

The study revealed that most of the practical activities designed by teachers were procedural in nature as they were characterised by: learners following laid down procedures, learners not given an opportunity to come up with alternative procedures and the objectives were mostly at low levels of cognitive domain. It was also noted that the focus of most of the practical activities was to expose learners to pieces of apparatus, verify and confirm what was discussed during theory lessons. As a result there were minimal opportunities for learners to think creatively, construct knowledge and understanding of chemistry concepts. The practical activities did not foster the development of a wider range of science process skills and learners were unable to construct meaning out of the data they collected.

\section{Recommendations}

In light of the findings of the study, below are some of the recommendations made:

i. There is need for science teacher educators to strengthen their education programs in terms of student exposure to practical activities especially investigative ones.

ii. Science standard officers should organise workshops and continuous professional development (CPDs) for chemistry teachers to train them on how to design practical activities.

iii. Chemistry teachers should design practical activities that provide opportunities for learners to understand chemistry concepts and develop science process skills.

iv. Chemistry teachers should design practical activities as a means to teach chemistry topics in the syllabus.

v. There is need for longitudinal study to be conducted so as to get a clearer picture of the nature of chemistry practical activities designed and delivered.

vi. Future research should endeavour to extend the scope of this study using mixed method approach.

\section{References}

Abrahams, I and Millar, R. (2009). Practical work: making it more effective. School Science Review, 91 (334), 59-64.

Abrahams, I. and Reiss, M. J. (2012). Practical work: Its effectiveness in primary and secondary schools in England. Journal of Research in Science Teaching, 49(8), 1035-1055

Ary,M., Jacobs,L.C., and Sorensen,C.,(2010). Introduction to Research in Education Wadsworth: Canada.

Chiappetta, E.L and Koballa, T.R. (2010). Science Instructions in the middle and secondary schools: Developing fundamental knowledge and skills for teaching $7^{\text {th }} \mathrm{Ed}$. Pearson $\mathrm{OH}$ : Columbus.

Chocha, S. E, Namayanga, K. C and Ndhlovu, H. G.,(2014.) Teaching science practically: An assessment of teacher competences on O-level biology practical work in Zambia. Zambia Journal of Teacher Professional Growth, 2 (1), 26-38.

Cohen, L., Manion, L and Morrison, K., (2007). Research methods in education. Routledge New York.

Curriculum Development Centre, CDC. (2013). Zambia National Education Curriculum Framework. Lusaka.

Emereole, H. U. (2009). Learners' and Teachers' Conceptual Knowledge of Science Processes: The Case of 
Botswana. International Journal of Science and Mathematics Education, 7 (3), 1033-1056.

Examination Council of Zambia, ECZ. (2014). Performance analysis report. Lusaka

Hodson, D. (1991). Practical work in science: Time for a reappraisal. Studies in Science Education, 19(1), $175-$ 184.

Ituma, M., Twoli, N and Khatete, D (2015). Chemistry teachers' role in changing practical work from simple 'hands on' activities to more of 'minds on' activities. International Journal of Humanities and Social Science.

Jimmi, C. (2014). Teachers competency in the teaching and learning of chemistry practical. Meditterranean Journal of Social Sciences. MCSER publishing, Rome-Italy, 5(8), 312-321.

Katane, G and Selvi,M (2006). Teacher competence and further education as priorities for sustainable development of rural school in lativa. Journal of Teacher Education and Training, 6 (200), 41-59.

Machina, J.M. (2012). Prospective teachers' preparedness to facilitate at secondary school level in Nairobi teaching practice zone. Thesis

Mbewe, S. Chabalengula, V. M. and Mumba, F. (2010). Pre-service teachers' familiarity, interest and conceptual understanding of science process skills. Problems of Education in the Twenty- First Century 22 (1) 76-86.

Merriam, S. B. (1998). Qualitative research and case study applications in education. Jossey Bass. San Francisco

Millar, R. (2004). The role of practical work in the teaching and learning of science. Paper prepared for the Committee: High School Science Laboratories: Role and Vision, National Academy of Sciences, Washington, DC.

Millar, R. (2010). Good practice in science teaching. Open University Press. Maidenhead.

Mwangi, J.T. (2016) Effect of chemistry practicals on students' performance in chemistry in public secondary schools of Machakos and Nairobi Counties in Kenya. PHD Thesis: University of Nairobi, Nairobi.

Nkoya, S. (2008) Chemistry teachers' use of learner-centered strategies in large classes: The case of selected schools in Kitwe district. Masters Dissertation, University of Zambia. Lusaka

Olufsen, M., Petrusevski, V., Hans-Georg, K., and Stojanovsk, M (2015). Practical work in chemistry, its goals and effects. Research gate.

Osborne, J. (1993). Alternatives to practical work. School Science Review, 75 (271), 117- 123.

Schunk, D. H (2012) Learning theories: An educational perspective $6^{\text {th }}$ Ed, Pearson education Inc. Boston.

Schwartz, R. S., Lederman, N. G. and Crawford, B. A. (2004). Developing views of nature of science in an authentic context: An explicit approach to bridging the gap between nature of science and scientific inquiry. International Journal of Science Education, 88(4), 610-645.

Vygotsky, L. S. (1978). Mind in society: The development of higher psychological processes. MA: Harvard University Press. Cambridge.

Wellington, J. (2002). Practical work in science: Time for a reappraisal: In practical work in school science; which way now? London: Routledge

Yin, R. K. (2012). Applications of case study research $3^{\text {rd }}$ ed. Thousand Oaks, CA: Sage. 